\title{
Karakteristik Infiltrasi dan Potensi Irigasi di Lahan Kering Kecamatan Bayan Kabupaten Lombok Utara
}

\author{
Characteristics of Infiltration and Irigation Potential In Dry Land \\ Bayan Distric of Lombok Utara Regency
}

\author{
I Dewa Gede Jaya Negara, Lilik Hanifah, Humairoh Saidah, Saiful Anwar \\ Jurusan Teknik Sipil Fakultas Teknik Universitas Mataram, INDONESIA. Tel. +62-0370 636126 \\ *corresponding author, email: jayanegara69@gmail.com
}

Manuscript received: 05-01-2021. Accepted: 18-03-2021

\begin{abstract}
ABSTRAK
Pembangunan pertanian dengan tanaman hortikultura di lahan kering, merupakan salah satu upaya pemerintah dalam meningkatkan produktivitas lahan kering sehingga dilakukan pencetakan sawah baru di daerah Bayan. Memperhatikan bahwa kemampuan infiltrasi lahan dan klasifikasinya merupakan faktor penting yang diperlukan dalam perencanaan irigasi untuk mendukung pengembangan pertanian hortikultura, sehingga perlu dilakukan penelitian lapangan tentang hal tersebut. Penelitian ini bertujuan untuk mengetahui karakteristik dan klasifikasi infiltrasi lahan serta menentukan kecenderungan irigasi yang dapat diterapkan. Uji infiltrasi lapangan dilakukan di Desa Anyar dan Sukadana dengan titik uji masing-masing 4 titik. Uji laju infiltrasi di lapangan dilakukan dengan alat double ring infiltrometer dan uji tanah di Laboratorium Geoteknik FT Unram. Analisis data digunakan rumus Horton sebagai pembanding dan hasil analisis dipresentasikan dalam bentuk tabel dan grafik, penyimpulan dilakukan secara deskriptip. Hasil penelitian menunjukkan bahwa laju infiltrasi rata-rata di Desa Anyar pada titik $1=26,90 \mathrm{~cm} / \mathrm{jam}$, titik $2=14,94 \mathrm{~cm} / \mathrm{jam}$, titik $3=27,33 \mathrm{~cm} / \mathrm{jam}$, dan titik $4=8,21 \mathrm{~cm} / \mathrm{jam}$ dengan tanah termasuk tanah liat berpasir.Klisifikasi laju infiltrasi titik 1 dan 3 termasuk sangat cepat, lokasi titik 2 termasuk cepat dan lokasi 4 termasuk agak cepat. Untuk Desa Sukadana laju infiltrasi diperoleh pada titik $1=43,52 \mathrm{~cm} / \mathrm{jam}$, titik $2=36,67 \mathrm{~cm} / \mathrm{jam}$, titik $3=12,86 \mathrm{~cm} / \mathrm{jam}$, dan titik $4=10,97 \mathrm{~cm} / \mathrm{jam}$, dengan kondisi tanah pasir ber tanah liat. Klasifikasi laju infiltrasi Sukadana titik 1 dan 2 termasuk sangat cepat dan titik 3 dan titik 4 termasuk agak cepat. Berdasarkan hasil uji infiltrasi tersebut maka untuk infiltrasi sangat cepat dan cepat berpotensi diterapkan irigasi pancar seperti sprinkler atau perforasi dan untuk infiltrasi agakcepat perbotensi diterapkan irigasi sistem tetes dan leb terbatas.
\end{abstract}

Kata kunci: klasifikasi; laju; cepat; sedang; lambat

\begin{abstract}
Agricultural development with horticultural crops on dry land is one of the government's efforts to increase dry land productivity so that new paddy fields are created in the Bayan area. Noting that land infiltration capability and its classification are important factors needed in irrigation planning to support the development of horticultural agriculture, so it is necessary to conduct field research on this matter.
\end{abstract}


This study aims to determine the characteristics and classification of land infiltration and determine the trend of irrigation that can be applied. Field infiltration tests were carried out in Anyar and Sukadana villages with 4 test points each. The infiltration rate test in the field was carried out using a double ring infiltrometer and a soil test at the Geotechnical Laboratory, Faculty of Engineering, Unram. Analysis of the data used Horton's formula as a comparison and the results of the analysis were presented in the form of tables and graphs, conclusions were made descriptively. The results showed that the average infiltration rate in Anyar Village was at point $1=26.90 \mathrm{~cm} /$ hour, point $2=14.94 \mathrm{~cm} /$ hour, point $3=$ $27.33 \mathrm{~cm} /$ hour, and point $4=8.21 \mathrm{~cm} /$ hour with soil including sandy clay. Infiltration rate classification of points 1 and 3 is very fast, point 2 is fast and location 4 is rather fast. For Sukadana Village the infiltration rate was obtained at point $1=43.52 \mathrm{~cm} /$ hour, point $2=36.67 \mathrm{~cm} /$ hour, point $3=12.86$ $\mathrm{cm} /$ hour, and point $4=10.97 \mathrm{~cm} /$ hour, with the condition sandy clay soil. Sukadana's infiltration rate classification points 1 and 2 are very fast and points 3 and 4 are rather fast. Based on the results of the infiltration test, for very fast and fast infiltration, it is potential to apply jet irrigation such as sprinklers or perforations and for rather fast infiltration, drip irrigation can be applied with limited drip system.

Key words: lassification; rate; fast; medium; slow

\section{PENDAHULUAN}

Kecamatan Bayan Kabupaten Lombok Utara termasuk salah satu wilayah lahan kering yang sangat berpotensi untuk dikembangkan sebagai usaha tani khususnya untuk pertanian hortikultura, ini dikarenakan ketersediaan air yang ada untuk irigasi sangat terbatas tetapi potensi lahan kering yang dapat dikembangkan sangat luas. Kecamatan Bayan merupakan salah satu daerah potensi lahan kering yang mendapat program pemerintah pencetakan sawah (petak lahan baru) untuk pengembangan pertanian dimasa mendatang. Pada lokasi tersebut biasanya dilakukan usahatani hanya sekali dalam satu tahun yaitu pada musim hujan untuk penanaman jagung, palawija maupun padi gogo (padi ladang) karena keterbatasan air. Dengan perubahan kondisi fisik lahan tersebut dan untuk mendukung pengembangan kegiatan pertanian di lokasi itu, sangat diperlukan informasi mengenai kemampuan infiltrasi lahan setelah dirubah menjadi petak lahan baru. Kemampuan infiltrasi lahan berupa laju infitrasi dan kategori infiltrasi dalam pengklasterannya menurut pustaka perlu diketahui, agar potensi pemanfaatan lahan kaitannya dengan aplikasi sistem irigasi dapat dilakukan lebih mudah. Mempertimbangkan banyak sistem irigasi yang ada baik yang tradisional maupun teknis, maka dengan hasil penelitian ini diharapkan dapat mengarahkan sistem irigasi yang akan digunakan untuk mendukung kegiatan usahatani masyarakat ke depan di lokasi itu.

Laju infiltrasi dipengaruhi oleh beberapa faktor, yaitu kedalaman genang dan tebal lapisan jenuh, kelembaban tanah, pemadatan oleh hujan, tanaman penutup, intensitas hujan, dan sifat-sifat fisik tanah. Metode yang biasa digunakan untuk menentukan laju infiltrasi adalah pengukuran dengan infiltrometer dan analisis hidrograf. Infiltrometer dibedakan menjadi infiltrometer genangan dan simulator hujan (rainfall simulators) (Triatmodjo, 2008).

Menurut O, Neal,1951 dalam Yunagardasari et al (2017) penelitian laju infiltrasi yang dilakukan pada beberapa jenis penggunaan lahan seperti lahan semak belukar, lahan kakau , lahan kebun kelapa dan lahan sawah digunakan acuan Tabel 1.

Tabel 1. Klasifikasi Laju Infiltrasi (Uhland and O, Neal, 1951) 


\begin{tabular}{ll}
\hline Kriteria & Laju Infiltrasi $(\mathrm{cm} / \mathrm{jam})$ \\
\hline Sangat Cepat & $>25,4$ \\
Cepat & $12,7-25,4$ \\
Agak Cepat & $6,3-12,7$ \\
Sedang & $2-6,3$ \\
Agak Lambat & $0,5-2$ \\
Lambat & $0,1-0,5$ \\
Sangat Lambat & $<0,1$ \\
\hline
\end{tabular}

Sumber : Yunagardasari et al,(2017)

Hasil penelitiannya menyebutkan bawa beberapa lahan dengan jenis tanah yang diteliti memiliki laju infitrasi yang beragam, dimana untuk lahan semak belukar laju infiltrasinya agak cepat sebesar $6,56 \mathrm{~cm} / \mathrm{jam}$, lahan kebun kakau tergolong sedang yaitu sebesar 2,0 cm/jam, pada lahan kebun kelapa dan dan lahan sawah tergolong agak lambat dengan laju infiltrasi lahan kebun kelapa 1,87 cm/jam dan lahan sawah sebesar 0,87 cm/jam. Berdasarkan hasil penelitian ini maka untuk jenis lahan yang diteliti di Anyar karena merupakan petakan lahan baru, hasil penelitian ini akan dirujuk sebagai dasar pembanding dan penentuan infiltrasi untuk irigasi dilokasi setempat.

Pengujian sifat fisik tanah bertujuan untuk mengetahui jenis tanah yang sedang diteliti yang diantaranya diantaranya kadar air, berat jenis dan gradasi ukuran butiran. Kadar air adalah perbandingan dari berat air dengan berat butiran padat dinyatakan dalam persen. Berat jenis tanah (Gs) adalah perbandingan antara berat volume butiran tanah $\left(\gamma_{\mathrm{s}}\right)$ dan berat volume air $\left(\gamma_{\mathrm{w}}\right)$ dengan isi yang sama pada temperatur tertentu. Besarnya butiran dijadikan dasar untuk pemberian nama dan klasifikasi tanah. Distribusi ukuran butiran adalah penentuan persentase berat butiran pada satu unit saringan, dengan menggunakan analisis saringan. Sedangkan tanah yang diameternya $\leq 0,075 \mathrm{~mm}$ menggunakan analisis sedimentasi (Hardiyatmo, 2006). Untuk kebutuhan pertanian, penentuan klasifikasi tanah digunakan sistem klasifikasi berdasarkan tekstur tanah yang dikembangkan oleh Departemen Pertanian Amerika (USDA).

Berdasarkan sistem klasifikasi taxsonomy, tanah untuk P Lombok terdiri dari 5 jenis tanah (Sistem nasional) yaitu Litosol, Aluvial, Kambisol, Grumussol dan Mediteran. Khusunya untuk jenis tanah Litosol termasuk Ustorthents menurut (SS-USDA,2014), dalam ( Priyono et al.,2019), dan jenis tanah ini terhampar pada sebagian besar wilayah lahan kering di Lombok Utara (Pemenang, Tanjung, Gangga, Kayangan, Bayan), sekitar 0,5 - $1 \mathrm{~km}$ dari pantai ke bagian Selatan (lereng atas). Tanah ini terbentuk dari bahan induk batu apung pada regim kelembaban tanah ustic (panas dan kering, bulan hujan $<3$ bulan). Solum tanah relative dangkal, horizon $\mathrm{A}<20 \mathrm{~cm}$ di atas $2-3$ horizon $\mathrm{C}$ bertekstur kasar dengan batu apung berukuran kecil-besar. Tanah berada pada bentang lahan (landsform) tua yang dicirikan dengan topografi datar - bergelombang (kemiringan $2-6 \%$ ), perubahan kedalaman solum tanah maupun jenis tanah (kompleks Ustorthets,Dystustepts dan Ustifluvents) tidak mengikuti 
perubahan kontur (kemiringan dan posisi lereng), sehingga batas unit jenis tanah tersebut sulit diidentifikasi berdasarkan perubahan kemiringan lereng, dalam (Priyono et al.,2019).

Berdasarkan kenampakan hamparan lahan dan vegetasi alami yang tumbuh pada tanah tersebut, tanah itu sangat miskin hara dan merupakan residu tanah yang telah tererosi selama ratusan-ribuan tahun. Tekstur pasiran, partikel primer didominasi oleh mineral rsisten (silicious, kaya sislikat), miskin unsur mikro dan makro, kecuali K, (Priyono et al.,2019).

Penelitian Suryanto.J (2017) menggunakan model infiltrasi terpilih dari hasil yang diperoleh menyimpulkan bahwa laju irigasi yang diberikan ke lahan pertanian di sarankan tidak melampaui laju infiltrasi lahan, agar menghidari terjadinya aliran permukaan. Hasil penelitian ini sangat berkaitan erat dengan pemilihan irigasi yang efisien untuk lahan kering yang baru dicetak, karena dilahan kering tidak diharapkan penggunaan air irigasi yang boros dan sedapat mungkin efektip untuk pertanian tanaman terpilih nantinya di lokasi penelitian ini.

Menurut Jaya Negara et al (2014) hasil uji irigasi tetes dilahan kering Pringgabaya menunjukkan bahwa pemberian irigasi selama 10 menit sampai 45 menit, mampu memberikan kedalaman basahan $30 \mathrm{~cm}$ dengan lengas sebesar $42 \%$ dari $14 \%$ sebelum pemberian irigasi tetes. Kemampuan infiltrasi lahan didaerah ini untuk diperbukitan sebesar 3,342 cm/jam (Randy, 2011), sedangkan pada lahan dataran sebesar 0,621 cm/jam (Haki, 2013). Jadi berdasarkan hasil uji tersebut maka besarnya capaian irigasi pada lahan sangat dipengaruhi oleh kemampuan infiltrasi lahan yang ada dan potensi tersebut sangat berkaitan sistem irigasi dan usaha pertanian.

\section{BAHAN DAN METODE}

Bahan yang digunakan untuk uji lapangan adalah air yang diambil dari permukiman penduduk sekitar dan peralatat uji infiltrasi dan alat bantu lainnya.

\section{Pelaksanaan Penelitian}

Penelitian merupakan uji lapangan yang dilakukan di dataran tinggi Kecamatan Bayan Kabupaten Lombok Utara dan di uji karakteristik tanah dilakukan di Laboratorium Geoteknik Fakultas Teknik Universitas Mataram.

1) Survey pendahuluan dilakukan dengan meninjau lokasi-lokasi yang telah ditargetkan untuk menentukan titik-titik pengujian lapangan dan pengambilan sampel tanah untuk uji di laboratorium.

2) Peralatan untuk pengukuran laju infiltrasi digunakan infiltrometer cincin ganda dan peralatan pembantu lainnya dengan peralatan pengujian seperti pada Gambar 2 


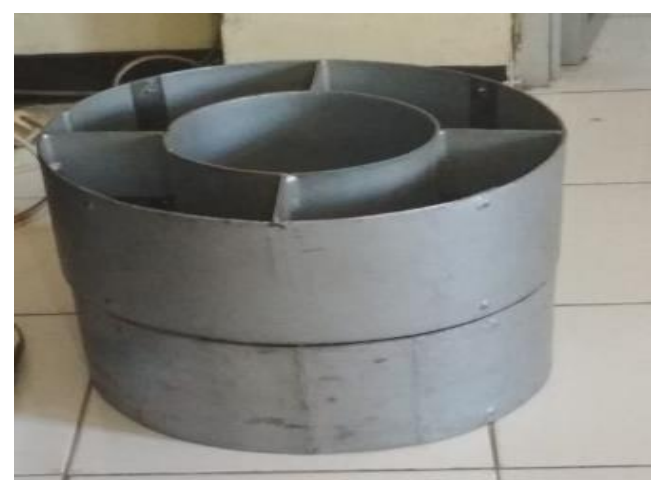

Gambar 2. Alat pengukuran laju infiltrasi cincin ganda

3) Pengukuran laju infiltrasi dilakukan berdasarkan perubahan tinggi muka air mengikuti langkah-langkah berikut:

\section{Pengujian Lapangan}

1) Meletakkan cincin dengan ujung runcing di bawah dan penampang cincin pada posisi level datar. Memasang piringan tutup di atas cincin dan pastikan tepat di pusat cincin. Kemudian tutup cincin dipukul dengan alat pemukul sampai kedalaman sekitar 5-10 cm umumnya cukup untuk menghindari aliran air ke samping. Menggunakan pukulan secukupnya untuk menghindari pecahnya permukaan tanah. Piringan tutup dilepaskan jika cincin sudah menancap ke dalam tanah.

2) Memasang lembaran pencegah percikan tanah saat pertama air di curahkan.Cincin silinder kemudian diberikan air hingga tinggi genangan sekitar $10 \mathrm{~cm}$. Mencatat waktu sejak mulai pengukuran $(\mathrm{t}=0)$ dan beda waktu antarpengukuran. Selang waktu yang dicantumkan, umumnya tiap 1 menit pada 10 menit pertama, tiap 2 menit pada menit ke 10 sampai 30, tiap 5 menit pada menit ke 30 sampai 60 dan tiap 15 menit setelah menit ke 60 sampai laju infiltrasi relatif konstan. Selang waktu dicantumkan juga berdasarkan laju infiltrasi yang terukur atau berdasarkan pengalaman lapangan pelaksana pengukuran. Air ditambahkan kembali untuk menjaga kedalaman yang konstan di dalam lubang. pengukuran menjadi laju infiltrasi dengan persamaan:

3)

$$
\text { Laju infiltrasi }=\frac{\Delta h}{\Delta t} \times 60
$$

dengan: $\mathrm{f}=$ laju infiltrasi $(\mathrm{cm} / \mathrm{jam}), \Delta h=$ perubahan tinggi muka air tiap selang waktu $(\mathrm{cm}), \Delta t=$ selang waktu pengukuran (menit).

\section{Analisis Data}

Analisis data dilakukan terhadap laju infiltrasi lapangan, kapasitas infiltrasi, klasifikasi infiltrasi, analisis sifat fisik tanah dan analisis potensi irigasi. Hasil analisis dipresentasikan dalam bentuk table dan grafik, dan disimpulkan secara deskriptif. 


\section{HASIL DAN PEMBAHASAN}

Pengujian sifat fisik terhadap sampel tanah dimaksudkan untuk mengetahui kadar air, serta jenis tanah berdasarkan Klasifikasi berdasarkan tekstur oleh Departemen Pertanian Amerika Serikat (USDA). Adapun sifat fisik tanah yang diuji antara lain: kadar air, berat jenis, serta analisa ukuran butir dengan ayakan dan hydrometer.

Tabel 1. Hasil analisis sifat fisik tanah

\begin{tabular}{lccl}
\hline Lokasi & $\begin{array}{c}\text { Kadar Air } \\
(\%)\end{array}$ & $\begin{array}{c}\text { Berat Jenis } \\
\left(\mathrm{gram} / \mathrm{cm}^{3}\right)\end{array}$ & Klasifikasi tanah \\
\hline Anyar 1 & 11,03 & 2,19 & Tanah liat berpasir \\
Anayar 2 & 8,80 & 2,72 & Tanah liat berpasir \\
Anyar 3 & 10,88 & 2,61 & Tanah liat berpasir \\
Anyar 4 & 15,25 & 2,54 & Tanah liat berpasir \\
Sukadana 1 & 4,71 & 2,70 & Pasir bertanah liat \\
Sukadana 2 & 4,37 & 2,65 & Pasir bertanah liat \\
Sukadana 3 & 4,10 & 2,59 & Pasir bertanah liat \\
Sukadana 4 & 3,62 & 2,55 & Pasir bertanah liat \\
\hline
\end{tabular}

Sumber: hasil analisis

Berdasarkan Tabel 1. dapat dilihat nilai kadar air, berat jenis tanah, dan klasifikasi tanah pada masing-masing titik di Desa Anyar dan Desa Sukadana. Adapun klasifikasi tanah di Desa anyar di semua titik termasuk tanah liat berpasir, sedangkan di Desa Sukadana termasuk klasifikasi pasir bertanah liat.

Berdasarkan Gambar 3, grafik perbandingan laju infiltrasi pada beberapa lokasi pengujian di Desa Anyar yang menunjukkan laju infiltrasi yang diperoleh berbeda.

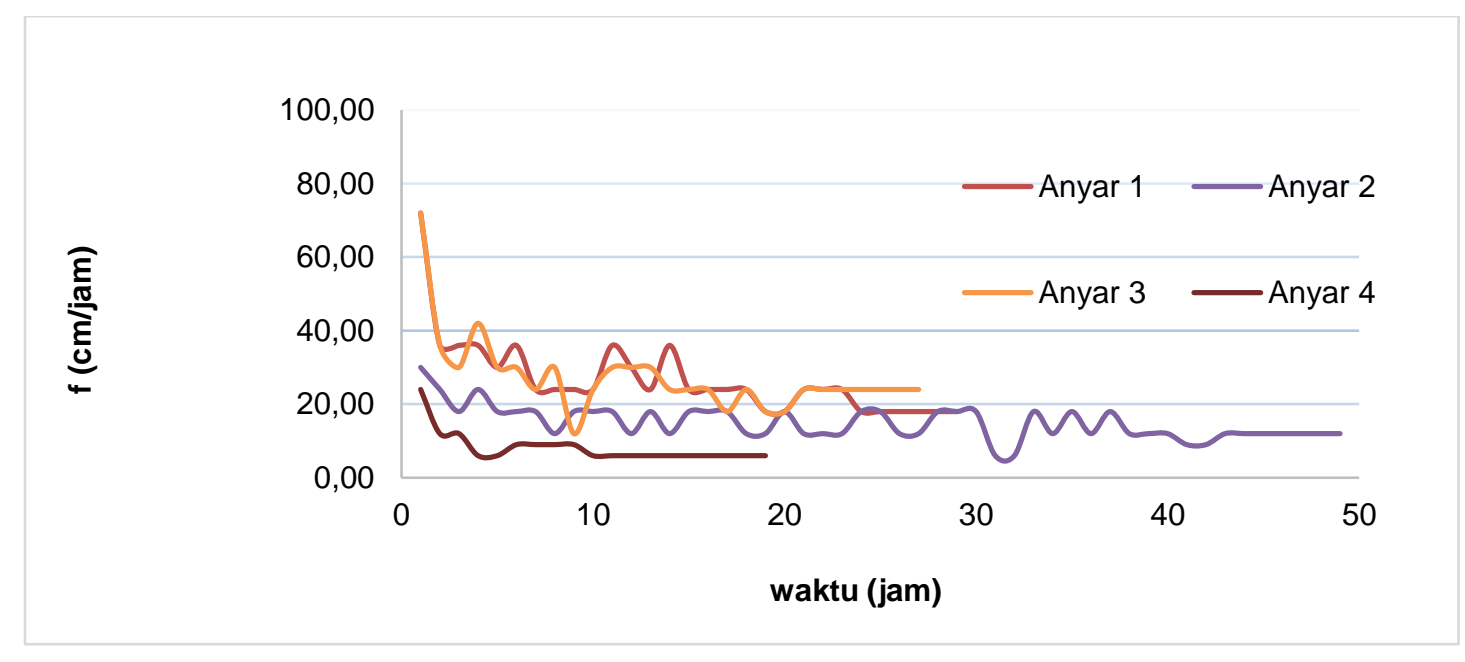

Gambar 3. Grafik perbandingan laju infiltrasi di Desa Anyar 
Laju infiltrasi awal (f0) terbesar terjadi pada titik 1 dan titik 3 dengan nilai yang sama, akan tetapi waktu yang dibutuhkan sampai laju infiltrasi konstan (fc) terlama terjadi pada titik 2, sedangkan untuk laju infiltrasi awal (f0) terkecil terjadi pada titik 4, serta waktu yang dibutuhkan sampai laju infiltrasi konstan (fc) pada titik 4 tercepat dibandingkan dengan keempat titik tersebut.

Tabel 2. Rekapitulasi nilai f0, fc dan f rata-rata di Desa Anyar

\begin{tabular}{cccc}
\hline lokasi & $\mathrm{f0}(\mathrm{cm} / \mathrm{jam})$ & $\mathrm{Fc}(\mathrm{cm} / \mathrm{jam})$ & f rata-rata $(\mathrm{cm} /$ menit $)$ \\
\hline Anyar 1 & 72,00 & 18,00 & 26,90 \\
Anyar 2 & 30,00 & 12,00 & 14,94 \\
Anyar 3 & 72,00 & 24,00 & 27,33 \\
Anyar 4 & 24,00 & 6,00 & 8,21 \\
\hline
\end{tabular}

Sumber: hasil analisis

Berdasarkan Tabel 2. dapat dilihat bahwa laju infiltrasi awal terbesar terjadi pada titik 1 dan titik 3 dengan nilai laju infiltrasi awal (f0) $=72 \mathrm{~cm} /$ jam dengan nilai fc terbesar terjadi pada titik $3=24 \mathrm{~cm} /$ jam sedangkan nilai $\mathrm{f}$ rata-rata terbesar terjadi pada titik $3=17,84 \mathrm{~cm} / \mathrm{menit}$. Untuk nilai laju infiltrasi awal (f0) terkecil berdasarkan Tabel 4.5 terjadi pada titik $4=24$ $\mathrm{cm} /$ jam serta dengan nilai kapasitas infiltrasi (fc) terkecil $=6 \mathrm{~cm} / \mathrm{jam}$ dan nilai laju infiltrasi rata-rata terkecil $=8,21 \mathrm{~cm} /$ menit.

Grafik ilustrasi pencapaian laju infiltrasi di Desa Sukadana dapat dilihat pada Gambar 6. Pada gambar tersebut diketahui bahwa laju infiltrasi awal (f0) terbesar $102 \mathrm{~cm} / \mathrm{jam}$ diperoleh pada lokasi uji titik 1, dengan waktu pencapaian laju infiltrasi konstan (fc) terbesar $36 \mathrm{~cm} / \mathrm{jam}$. Laju infiltrasi awal (f0) terendah diperoleh pada lokasi uji titik 4, dengan pencapaian laju infiltrasi konstan (fc) tercepat terjadi pada titik 3 dari ke 4 lokasi yang diuji.

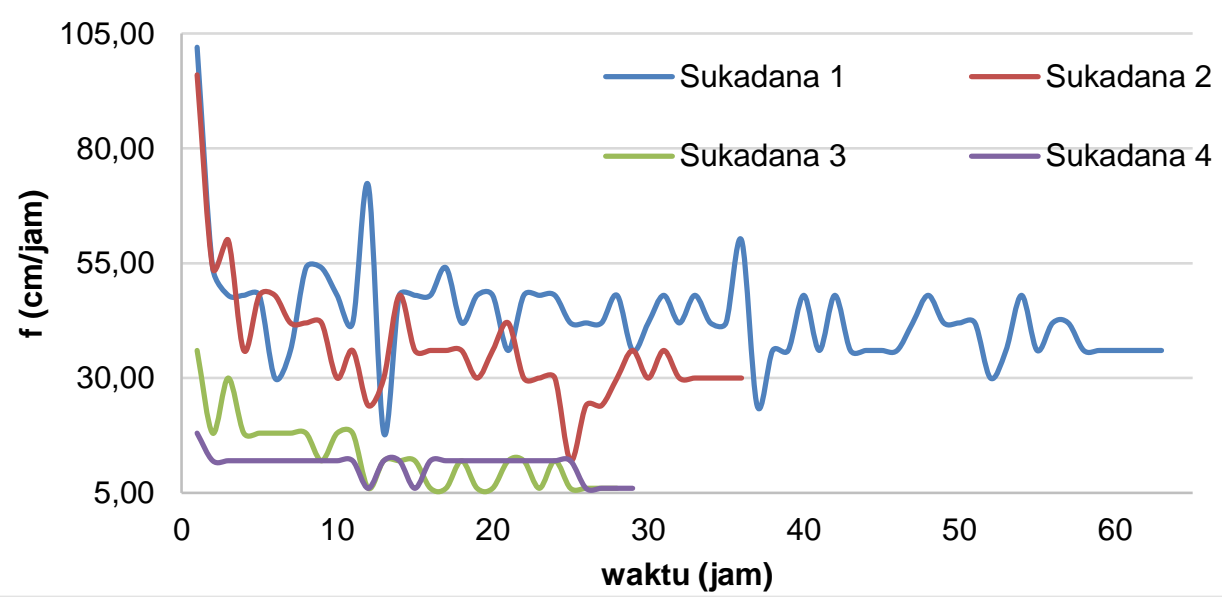

Gambar 4. Karakteristik laju infiltrasi Lokasi Sukadana

Berdasarkan Tabel 3. dapat dilihat bahwa laju infiltrasi awal terbesar diperoleh pada lokasi uji titik 1 dengan nilai f rata-rata (fc) terbesar yaitu $43,52 \mathrm{~cm} / \mathrm{jam}$, lihat tabel berikut. 
Tabel 3. Rekapitulasi nilai f0, fc dan f rata-rata di Desa Sukadana

\begin{tabular}{cccc}
\hline Lokasi & $\mathbf{f}(\mathbf{0})(\mathbf{c m} / \mathbf{j a m})$ & $\begin{array}{c}\mathbf{f}(\mathbf{c}) \\
(\mathbf{c m} / \mathbf{j a m})\end{array}$ & $\begin{array}{c}\text { f rata-rata } \\
(\mathbf{c m} / \mathbf{j a m})\end{array}$ \\
\hline Sukadana 1 & 102,00 & 36,00 & 43,52 \\
Sukadana 2 & 96,00 & 30,00 & 36,67 \\
Sukadana 3 & 36,00 & 6,00 & 12,86 \\
Sukadana 4 & 18,00 & 6,00 & 10,97 \\
\hline
\end{tabular}

Sumber: hasil analisis

Untuk nilai laju infiltrasi awal terkecil diperoleh pada titik 4 sebesar $18 \mathrm{~cm} / \mathrm{jam}$ serta dengan nilai kapasitas infiltrasi (fc) terkecil diperoleh pada titik 3 dan titik 4 sebesar $6 \mathrm{~cm} / \mathrm{jam}$, sedangkan nilai f rata-rata terkecil diperoleh pada titik 4 sebesar 10,97 cm/jam.

Klasifikasi Infiltrasi Lahan.

Hasil analisis klasifikasi laju infiltrasi pada masing-masing titik lokasi infiltrasi lapangan untuk lokasi Desa Anyar dapat dilihat pada Tabel 4

Tabel 4. Klasifikasi laju infiltrasi hasil analisis lokasi Desa Anyar

\begin{tabular}{lcl}
\hline Lokasi & f rata-rata $(\mathrm{cm} / \mathrm{jam})$ & Klasifikasi laju infiltrasi \\
\hline Anyar 1 & 26,90 & Sangat cepat \\
Anyar 2 & 14,94 & Cepat \\
Anyar 3 & 27,33 & Sangat cepat \\
Anyar 4 & 8,21 & Agak cepat \\
\hline rata-rata & 19,34 & Cepat
\end{tabular}

Sumber: hasil analisis

Berdasar hasil pada Tabel 5 di Desa Anyar, klasifikasi laju infiltrasi berdasarkan klasifikasi Uhland and O'neal (1951) dalam Yunagardasari et al (2017) memiliki klasifikasi yang berbeda, dimana laju infiltrasi pada lokasi titik 1 diperoleh laju infiltrasi rata-rata sebesar 26,90 $\mathrm{cm} / \mathrm{jam}$ termasuk sangat cepat. Sedangkan laju infiltrasi rata-rata terendah diperoleh pada lokasi titik 4 sebesar 8,21 cm/jam dan tergolong laju infiltrasi agak cepat. Berdasarkan hasil uji tersebut, laju infiltrasi yang diperoleh rata-rata sebesar 19,34 cm/jam, termasuk klasifikasi laju infiltrasi cepat.

Tabel 5.Klasifikasi laju infiltrasi hasil analisis lokasi Desa Sukadana

\begin{tabular}{lcl}
\hline \multicolumn{1}{c}{ Lokasi } & f rata-rata $(\mathbf{c m} / \mathbf{j a m})$ & Klasifikasi laju infiltrasi \\
\hline Sukadana 1 & 43,52 & sangat cepat \\
Sukadana 2 & 37,33 & sangat cepat \\
Sukadana 3 & 13,07 & Cepat \\
Sukadana 4 & 10,97 & agak cepat \\
\hline rata-rata & 26,22 & Sangat cepat
\end{tabular}

Sumber: hasil analisis

Berdasarkan hasil analisis pada Tabel 5. Klasifikasi laju infiltrasi di Desa Sukadana diperoleh bahwa, klasifikasi laju infiltrasi berdasarkan klasifikasi Uhland and O'neal (1951) memiliki klasifikasi yang berbeda, dimana laju infiltrasi pada titik lokasi 1 dan lokasi 2 dengan laju 
infiltrasi rata-rata sebesar 43,55 cm/jam dan $37,33 \mathrm{~cm} /$ jam termasuk laju infiltrasi sangat cepat. Laju infiltrasi rata-rata terendah diperoleh dilokasi titik lokasi 4 yaitu sebesar 10,97 cm/menit, termasuk klasifikasi laju infiltrasi agak cepat. Dilokasi Sukadana diperoleh laju infiltrasi ratarata sebesar 26,22 cm/jam tersebut, termasuk klasifikasi laju infiltrasi sangat cepat.

\section{Klasifikasi Tanah.}

Berdasarkan hasil analisis data tiga sampel tanah setiap titik lokasi studi diketahui bahwa lokasi studi Anyar merupakan lahan kering dalam bentuk petak-petakan lahan baru, dan untuk lokasi di Sukadana merupakan lahan berbentuk lereng dan tidak merupakan petak sawah baru. Hasil uji tanah dari ke dua lokasi tersebut ditunjukkan pada Gambar 5 dan Gambar 6.

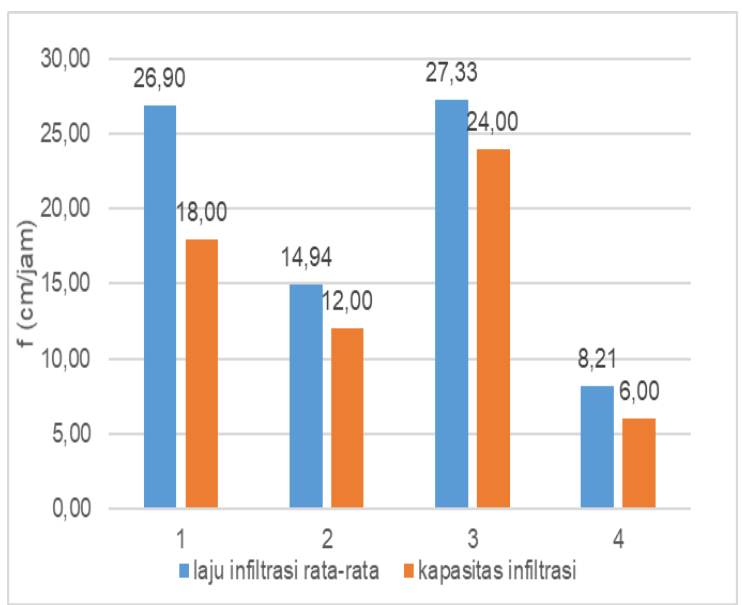

Gambar 5. Laju infiltrasi di Desa Anyar

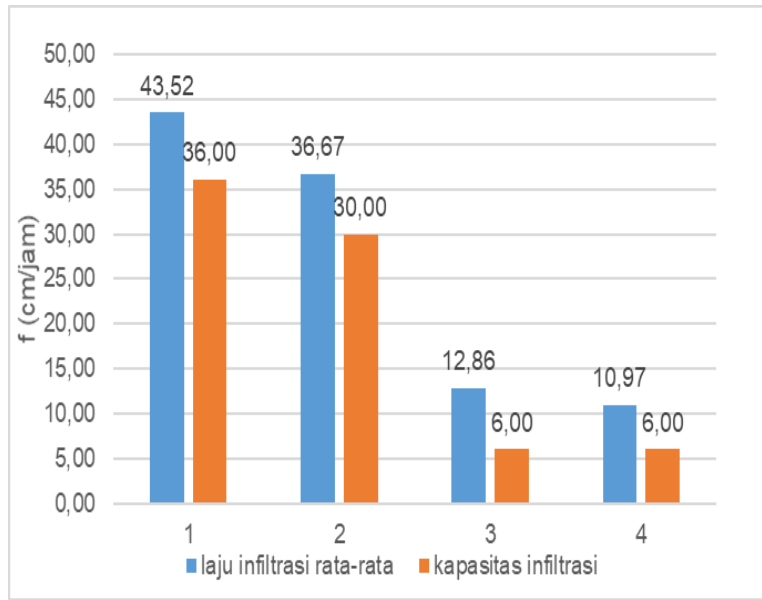

Gambar 6. Laju Infiltrasi Sukadana

Untuk klasifikasi jenis tanah dilokasi studi di Desa Anyar termasuk dalam klasifikasi jenis tanah liat berpasir, sedangkan untuk lokasi Sukadana termasuk dalam klasifikasi pasir bertanah liat dan kondisinya lebih poros dari pada tanah Desa Anyar. Secara visual tanah di ke dua lokasi studi sangat berbeda karakternya sehingga potensi untuk pemanfaatan tanah tersebut perlu pemilihan jenis tanaman dan sistem irigasi yang memadai agar dalam aksi usahatani dapat memberikan manfaat kepada masyarakat.

\section{Potensi Aplikasi Irigasi}

Berdasarkan hasil uji infiltrasi lapangan dan pertimbangan jenis tanah yang ada, dan untuk dapat mendukung pemberian air pada tanaman pada lahan harus mempertimbangkan kemampuan infiltrasi lahan. Kemampuan infiltrasi lahan lokasi anyar untuk laju infiltrasi yang diharapkan untuk lahan pertanian adalah tanah dengan kemapuan infiltrasi sedang sampai agak cepat. Untuk kegiatan pertanian dimana irigasi akan diperlukan dalam waktu yang terbatas karena tanaman tidak tahan terhadap kebasahan berlebihan, maka sebaiknya irigasi dipilih sesuai kebutuhan tanaman tersebut. Jadi dalam pemilihan teknik irigasi selain mempertimbangkan potensi infiltrasi tanah, porsi tanah halus terhadap butir kasarnya, juga perlu diperhatikan jenis tanaman yang akan dibudidayakan dilahan tersebut. Dengan adanya porsi butiran halus pada tanah maka akan memberi dua manfaat yaitu pertama air irigasi 
berpeluang dapat meresap ke arah lateral dipermukaan dan lapisan tanah dan meresap vertikal ke dalam tanah mencapai kedalaman perakaran tertentu, yang ke dua air irigasi dapat disimpan lebih lama didalam tanah sehingga intensitas irigasi dapat dilakukan lebih jarang. Hal ini menjadi pertimbangan penting karena akan menyangkut operasional irigasi dan perkembangan pertumbuhan tanaman dilahan. Berdasarkan potensi lahan yang ada maka pada Tabel 6 ditunjukan potensi irigasi yang mungkin diterapkan pada lahan tersebut.

Tabel 6. Klasifikasi laju infiltrasi dan potensi irigasi di lokasi uji Sukadana

\begin{tabular}{|c|c|c|c|c|}
\hline Lokasi & $\begin{array}{l}\text { f rata-rata } \\
(\mathrm{cm} / \mathrm{jam})\end{array}$ & $\begin{array}{c}\text { Klasifikasi } \\
\text { laju } \\
\text { infiltrasi }\end{array}$ & $\begin{array}{l}\text { Potensi } \\
\text { Aplikasi } \\
\text { Irigasi }\end{array}$ & $\begin{array}{c}\text { Keterangan } \\
\text { Kondisi } \\
\text { lahan }\end{array}$ \\
\hline Sukadana 1 & 43,52 & $\mathrm{SC}$ & pancar/tetes & Pasir bertanah liat \\
\hline Sukadana 2 & 37,33 & SC & pancar/tetes & Pasir bertanah liat \\
\hline Sukadana 3 & 13,07 & $\mathrm{C}$ & tetes/ tradisional & Pasir bertanah liat \\
\hline Sukadana 4 & 10,97 & $\mathrm{AC}$ & tradisional /tetes & Pasir bertanah liat \\
\hline
\end{tabular}

(Sumber: hasil analisis),

Keterangan: $\mathrm{SC}=$ sangat cepat, $\mathrm{S}=$ Sedang, $\mathrm{AC}=$ Agak Cepat, $\mathrm{C}=$ Cepat

Berdasarkan hasil pengujian laju infiltrasi di lahan Sukadana dimana kondisi tanah pada daerah bagian bawah yang lebih dominan pasiran dan dibeberapa tempat juga terdapat lanauan dan pada lokasi 3 diperoleh fc 13,07 cm/jam dan lokasi 4 dengan fc 10,97 cm/jam. Bila dilihat hasil penelitian Yunagardasari et al (2017) bahwa dilokasi lahan kering ini laju infiltrasinya sangat besar, sehingga untuk lahan pertanian dengan irigasi penggenangan memang sangat tidak disarankan karena akan boros air.

Untuk itu sebaiknya pada lokasi lahan dengan infiltrasi sangat cepat dan cepat perlu mempertimbangkan untuk penggunaan irigasi sistem pancar apakah itu sistem irigasi sprinkler atau pipa perforasi dan sistem tetes, karena sistem rigasi tersbut jatuhnya air dilahan akan langsung meresap ke dalam tanah dan perakaran tanaman. Sedangkan untuk lahan dengan infiltrasi agak cepat masih bisa diterapkan sistem irigasi leb (penggenangan sesaat) bukan seperti irigasi lahan basah, dan juga sistem tetes pada luas lahan terbatas saja.

Tabel 7. Klasifikasi laju infiltrasi dan potensi Irigasi di lokasi uji Anyar

\begin{tabular}{llll}
\hline Lokasi & f rata-rata & $\begin{array}{l}\text { Klasifikasi } \\
\text { laju infiltrasi }\end{array}$ & \multicolumn{2}{c}{ Potensi Keterangan } \\
& $(\mathrm{cm} / \mathrm{jam})$ & Aplikasi Irigasi & Kondisi
\end{tabular}

\begin{tabular}{lrrl}
\hline Anyar 1 & 26,90 & SC & Pancaran/Tetes Tanah liat ber pasir \\
Anyar 2 & 21,94 & $\mathrm{C}$ & Pancaran/ Tetes Tanah liat berpasir \\
Anyar 3 & 27,33 & SC & Pancaran/Tetes Tanah Liat berpasir \\
Anyar 4 & 8,21 & AC & Leb terbatas/TetesTanah Liat berpasir
\end{tabular}

(Sumber: hasil analisis), Keterangan: $\mathrm{SC}=$ sangat cepat, $\mathrm{S}=$ sedang, $\mathrm{AC}=$ agak cepat, $\mathrm{C}=$ cepat Untuk lokasi Anyar lokasi-lokasi yang mempunyai peluang untuk kegiatan pertanian praktis ada pada lokasi lahan 2 yang berada diposisi di lereng atas perbukitan dengan fc sebesar 14,95 $\mathrm{cm} /$ jam dan lokasi 4 dibagian lereng bawah dengan $\mathrm{fc} 8,21 \mathrm{~cm} / \mathrm{jam}$. Berdasarkan data yang 
diperoleh pada lokasi 4 yang memiliki laju infiltrasi terendah masih berpotensi diterapkan sistem irigasi penggenangan sesaat ( tidak seperti penggenangan lahan basah), sedangkan untuk lahan dengan laju infiltrasi besar cenderung dengan sistem irigasi yang efisien seperti sistem irigasi pancar dan tetes. Untuk irigasi tetes pvc bila diterapkan pada lokasi dalam 45 menit irigasi akan dapat mencapai kedalaman tanah sampai $30 \mathrm{~cm}$ (jaya negara et al, 2014), dan untuk tanaman hortikultura kedalaman capaian air irigasi tersebut diperkirakan akan memenuhi kebutuhan tanamannya. Dalam prakteknya sistem irigasi terpilih nantinya perlu memperhatikan laju irigasi yang diberikan ke lahan pertanian untuk tidak melampaui laju infiltrasi lahan, agar menghidari terjadinya aliran air dipermukaan, Suryanto.J (2017). Dengan memperhatikan besarnya infiltrasi yang diperoleh pada lokasi studi, maka aplikasi sistem irigasi yang berpotensi dapat dilihat pada Tabel 8 .

Tabel 8. Infiltrasi lahan dan potensi aplikasi sistem irigasi dilokasi studi

\begin{tabular}{lrl}
\hline $\begin{array}{l}\text { Sistem Irigasi } \\
(\mathrm{cm} / \text { jam })\end{array}$ & Infiltras & Kondisi Tahah \\
\hline Tetes & $8-25$ & Tanah Liat berpasir - Pasir ber tanah liat \\
Pancaran & 25 & Tanah poros
\end{tabular}

(Sumber: hasil analisis)

Untuk aplikasi irigasi tetes dengan durasi 1 jam diperkirakan akan dapat mencapai kedalaman tanah sekitar $8 \mathrm{~cm}$ untuk lahan kering yang berlereng dengan ketebalan lapisan permukaan sekitar $10 \mathrm{~cm}$ dan diperkirakan akar akan dominan berkembang ke arah mendatar. Akan tetapi untuk lahan dengan kedalaman olah tanah yang dapat mencapai $25 \mathrm{~cm}$, dalam kondisi tersebut juga masih bisa diterapkan sistem irigasi tetes tetapi dengan luas lahan olah yang terbatas. Memperhatikan sumber air yang potensial diperoleh berasal dari jaringan irigasi dibagian daerah atas, maka penerapan irigasi tetes sangat berpeluang dilokasi-lokasi tersebut. Akan tetapi untuk penerapan irigasi pancaran pada lahan yang masih berkondisi berbukit dan memiliki potensi angin yang kencang, sistem tetes masih potensial diterapkan pada tempattempat tersebut.Untuk aplikasi sistem irigasi pancar tidak disarankan karena air tidak tersedian yang cukup dan lahan kondisinya banyak terhalang pepohonan yang besar, kondisi tersebut diperkirakan tidak efektif diaplikasikan.

\section{KESIMPULAN}

Hasil penelitian menunjukkan bahwa laju infiltrasi rata-rata di Desa Anyar pada titik $1=$ $26,90 \mathrm{~cm} / \mathrm{jam}$, titik $2=14,94 \mathrm{~cm} / \mathrm{jam}$, titik $3=27,33 \mathrm{~cm} / \mathrm{jam}$, dan titik $4=8,21 \mathrm{~cm} / \mathrm{jam}$. Tanah di Anyar termasuk tanah liat berpasir dengan klisifikasi laju infiltrasi titik 1 dan 3 termasuk sangat cepat, lokasi titik 2 termasuk cepat dan lokasi 4 termasuk agak cepat. Sedangkan untuk Desa Sukadana diperoleh laju infiltrasi pada titik $1=43,52 \mathrm{~cm} / \mathrm{jam}$, titik $2=36,67 \mathrm{~cm} / \mathrm{jam}$, titik $3=12,86 \mathrm{~cm} / \mathrm{jam}$, dan titik $4=10,97 \mathrm{~cm} / \mathrm{jam}$, dengan kondisi tanah pasir ber tanah liat. Klasifikasi laju infiltrasi Sukadana titik 1 dan 2 termasuk sangat cepat dan titik 3 dan titik 4 termasuk agak cepat. Berdasarkan hasil uji infiltrasi tersebut maka untuk infiltrasi sangat cepat 
dan cepat berpotensi diterapkan irigasi pancar seperti sprinkler atau perforasi dan untuk infiltrasi agak cepat perpotensi diterapkan irigasi sistem tetes dan leb terbatas.

\section{DAFTAR PUSTAKA}

Hardiyatmo. 2006. Mekanika Tanah 1.

Hastuti. 1982. Kadar Lengas Tanah, http://tonothemycry.blogspot.co.id// 22 Oktober 2017.

Priyono J.,Yasin I.,Dahlan M.,Bustan. 2019. Identification the properties, Charakteritics, and Type of main Soils in Lombok Island, Jurnal Sains Teknologi dan Lingkungan, Vol 5 No1, ISSN: 2477-0329 .hal 19- 24, LPPM Unram, Mataram

Randy R. 2012. Analisis krakteristik Infiltrasi Hamparan Lahan Kering di Desa Pringgabaya Utara, Skripsi,FT.Unram, Mataram

Haki Y.2013. Analisis Peningkatan Potensi Infiltrasi pada Tanah Berbutir Halus dengan Mencapurkan Tanah berbutir kasar di Lahan kering Desa pringgabaya Utara. Skripsi FT Unram, Mataram

Jaya Negara.IDG., Saadi Y., Putra IB. 2014. Karakteristik Perubahan Lengas Tanah pada Pemberian Irigasi Tetes Pipa PVC di Lahan Kering Pringgabaya Kabupaten Lombok Timur.Jurnal Spektrum Sipil, Vol 1 No 2, hal 112-211. ISSN 1858-4896

Suryanto.J.2017, Penentuan Laju infiltrasi di Lahan Pertanian Kecamatan Sangatta Selatan dengan Model Infiltrasi Terpilih, Jurnal Pertanian Terpadu. Vol 5 No 1 Juni 2017, hal 56-67.

Triatmodjo B. 2008. Hidrologi Terapan. Yogyakarta: Beta Offset.

Yunagardasari,C., Paloloang A K., Monde A. 2017. Infiltration Model in Different Landuse in Desa Tulo Kecamatan Dolo Kabupaten Sigi. e-J. Agrotekbis 5 (3) : 315 - 323, Juni 2017 ISSN : 2338-3011. 